\title{
Impact of type 2 diabetes mellitus on left ventricular diastolic function in patients with essential hypertension: evaluation by volume-time curve of cardiac magnetic resonance
}

Wei-feng Yan ${ }^{1+}$, Yue Gao ${ }^{1 \dagger}$, Yi Zhang ${ }^{1+}$, Ying-kun Guo ${ }^{2}$, Jin Wang ${ }^{1}$, Li Jiang ${ }^{1}$, Yuan Li ${ }^{1 *}$ and Zhi-gang Yang ${ }^{1 *}$ (D)

\begin{abstract}
Background: Essential hypertension and type 2 diabetes mellitus (T2DM) are two common chronic diseases that often coexist, and both of these diseases can cause heart damage. However, the additive effects of essential hypertension complicated with T2DM on left ventricle (LV) diastolic function have not been fully illustrated. This study aims to investigate whether T2DM affects the diastolic function of the LV in patients with essential hypertension using the volume-time curve from cardiac magnetic resonance (CMR).
\end{abstract}

Methods: A total of 124 essential hypertension patients, including 48 with T2DM [HTN(T2DM +) group] and 76 without T2DM [HTN(T2DM-) group], and 52 normal controls who underwent CMR scans were included in this study. LV volume-time curve parameters, including the peak ejection rate (PER), time to peak ejection rate (PET), peak filling rate (PFR), time to peak filling rate from end-systole (PFT), PER normalized to end-diastolic volume (PER/EDV), and PFR normalized to EDV (PFR/EDV), were measured and compared among the three groups. Multivariate linear regression analyses were performed to determine the effects of T2DM on LV diastolic dysfunction in patients with hypertension. Pearson correlation was used to analyse the correlation between the volume-time curve and myocardial strain parameters.

Results: PFR and PFR/EDV decreased from the control group, through HTN(T2DM - ), to HTN(T2DM +) group. PFT in the HTN(T2DM-) group and HTN(T2DM+) group was significantly longer than that in the control group. The LV remodelling index in the HTN(T2DM - ) and HTN(T2DM+) groups was higher than that in the normal control group, but there was no significant difference between the HTN(T2DM -) and HTN(T2DM+) groups. Multiple regression analyses controlling for covariates of systolic blood pressure, age, sex, and heart rate demonstrated that T2DM was independently associated with PFR/EDV $(\beta=0.252, p<0.05)$. The volume-time curve method has good repeatability, and there is a significant correlation between volume-time curve parameters (PER/EDV and PFR/EDV) and myocardial peak strain rate, especially circumferential peak strain rate, which exhibited the highest correlation $(r=-0.756 \sim 0.795)$.

\footnotetext{
*Correspondence: dr.liyuan@163.com; yangzg666@163.com

'Wei-feng Yan, Yue Gao and Yi Zhang are co-first authors

1 Department of Radiology, West China Hospital, Sichuan University, 37\#

Guo Xue Xiang, Chengdu 610041, Sichuan, China

Full list of author information is available at the end of the article
}

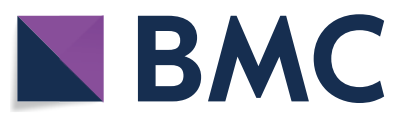

(c) The Author(s) 2021. This article is licensed under a Creative Commons Attribution 4.0 International License, which permits use, sharing, adaptation, distribution and reproduction in any medium or format, as long as you give appropriate credit to the original author(s) and the source, provide a link to the Creative Commons licence, and indicate if changes were made. The images or other third party material in this article are included in the article's Creative Commons licence, unless indicated otherwise in a credit line to the material. If material is not included in the article's Creative Commons licence and your intended use is not permitted by statutory regulation or exceeds the permitted use, you will need to obtain permission directly from the copyright holder. To view a copy of this licence, visit http://creativeco mmons.org/licenses/by/4.0/. The Creative Commons Public Domain Dedication waiver (http://creativecommons.org/publicdomain/ zero/1.0/) applies to the data made available in this article, unless otherwise stated in a credit line to the data. 
Conclusions: T2DM exacerbates LV diastolic dysfunction in patients with essential hypertension. The LV filling model changes reflected by the CMR volume-time curve could provide more information for early clinical intervention.

Keywords: Hypertension, Type 2 diabetes mellitus, Left ventricular diastolic dysfunction, Magnetic resonance imaging, Volume-time curve

\section{Background}

As two common chronic diseases that threaten human health, essential hypertension and type 2 diabetes mellitus (T2DM) frequently coexist. Approximately two thirds of patients with essential hypertension have impaired glucose tolerance, and hypertensive patients with type 2 diabetes have an increased risk of hospitalization and incidence of adverse cardiovascular events [1, 2]. Left ventricle (LV) diastolic dysfunction is one of the earliest manifestations of myocardial failure and is associated with abnormal blood pressure or glucose metabolism [3, 4]. Therefore, it is of great clinical significance to evaluate the synergistic effect of T2DM and essential hypertension on LV diastolic function. However, the contribution of T2DM to LV diastolic dysfunction in hypertension patients has not been fully elucidated.

Because of its excellent soft tissue resolution and multiplanar, multiparameter imaging, cardiac magnetic resonance (CMR) has become the gold standard for evaluating cardiac structure and function $[5,6]$. In previous studies, the volume-time curve parameters obtained by CMR have been considered a promising indicator of LV diastolic function $[7,8]$ and have been shown to play a role in the diagnosis and evaluation of several cardiovascular diseases [9-12]. To the best of our knowledge, no one has used this method to analyse the additive effects of essential hypertension complicated with T2DM on cardiac diastolic function. Therefore, this study attempted to analyse whether T2DM exacerbates LV diastolic dysfunction in essential hypertensive patients by using CMR volume-time curves.

\section{Materials and methods Study population}

This study was approved by the Clinical Trials and Biomedical Ethics Committee of West China Hospital of Sichuan University and carried out following the Declaration of Helsinki (2013 edition). The study subjects were essential hypertension patients who underwent CMR examination in our hospital from May 2016 to October 2020. Hypertension is defined as systolic blood pressure $\geq 140 \mathrm{mmHg}$ and/or diastolic blood pressure $\geq 90 \mathrm{mmHg}$ [13]. The patients with T2DM were screened out from patients with essential hypertension. The diagnosis of T2DM was based on the recommendations of the current guidelines of the American Diabetes
Association [14]. The exclusion criteria included heart failure, left ventricular ejection fraction (LVEF) $<50 \%$, coronary heart disease, atrial fibrillation, various congenital heart diseases, valvular heart disease, cardiomyopathy, hyperthyroidism, severe hepatopulmonary dysfunction, secondary hypertension, and estimated glomerular filtration rate $($ eGFR $)<30 \mathrm{~mL} / \mathrm{min} / 1.73 \mathrm{~m}^{2}$. In addition, patients with cardiac late gadolinium enhancement (LGE) caused by myocardial infarction or with CMR images of insufficient quality for postprocessing analysis were excluded. Healthy volunteers matched for age and sex with normal blood pressure and blood glucose from our image database were selected as the control group.

Finally, after further exclusion of several patients with unmatched age or sex, 76 essential hypertension patients without T2DM [HTN(T2DM-) group, 39 males and 37 females, mean age $56.43 \pm 11.3$ years, range 26-78 years], 48 essential hypertension patients with T2DM [HTN(T2DM+) group, 24 males and 24 females, mean age $57.69 \pm 12.46$ years, range $29-80$ years] and 52 healthy controls ( 26 males and 26 females; mean age $53.29 \pm 13.08$ years, range $25-76$ years) were enrolled in this study. All patients and controls underwent the same CMR examination.

\section{CMR protocol}

CMR was performed using a $3.0 \mathrm{~T}$ whole-body scanner (Trio Tim; Siemens Medical Solutions, Erlangen, Germany). All subjects were examined in the supine position. A manufacturer's standard ECG-triggering device and the breath-hold technique were used during the entire examination, and data acquisition was performed during the breath-holding period. Localized imaging, including imaging of the coronal, sagittal, and horizontal planes, was performed by using the True FISP sequence (echo time $1.33 \mathrm{~ms}$, repetition time $710 \mathrm{~ms}$, flip angle $10^{\circ}$, slice thickness $8 \mathrm{~mm}$, space between slices $24 \mathrm{~mm}$, field of view $290 \times 373 \mathrm{~mm}$, and matrix size $146 \times 224 \mathrm{~mm})$. A balanced steady-state free precession (bSSFP) sequence (field of view [FOV] $250 \times 300 \mathrm{~mm}$, repetition time [TR] $39.34 \mathrm{~ms}$, echo time [TE] $1.22 \mathrm{~ms}$, flip angle $40^{\circ}$, slice thickness $8 \mathrm{~mm}$, and matrix size $208 \times 139$ ) was used to acquire 8-12 continuous cine images from the mitral valve level to the LV apex in the short-axis view. Vertical LV 2- and 4-chamber long-axis view cine series were 
acquired as well. LGE images (FOV $400 \times 270 \mathrm{~mm}$; TR $750 \mathrm{~ms}$; TE $1.18 \mathrm{~ms}$; flip angle $40^{\circ}$, slice thickness $8 \mathrm{~mm}$ ) were obtained during the end-diastolic phase 10-15 min after intravenous administration of $0.2 \mathrm{~mL} / \mathrm{kg}$ gadolinium chelate contrast agent (Gadodiamide, GE Healthcare, Ireland).

\section{Image analysis}

An experienced radiologist analysed the CMR data on an offline workstation without seeing the clinical data and removed patients with LGE. All image postprocessing operations were performed following the latest International Cardiac Magnetic Resonance Association guidelines [15]. The images of eligible subjects were then analysed using offline postprocessing software (Argus, Siemens Medical Solutions, Erlangen, Germany) and offline commercial software (CVI42, v.5.10.2; Circle cardiovascular imaging, Calgary, Canada). Argus was used to draw the endocardial boundary of the LV on each short-axis image, and the volume-time curve parameters, including the peak ejection rate (PER), time to peak ejection rate (PET), peak filling rate (PFR), time to peak filling rate from end-systole (PFT), PER normalized to end-diastolic volume (PER/EDV), and PFR normalized to EDV (PFR/EDV), were obtained. The volume-time curve and the meaning of its parameters are shown in Fig. 1.
The end-systolic and end-diastolic endocardium and epicardium on the short axis were drawn by CVI42 to obtain routine cardiac function indexes, including LV EDV, endsystolic volume (ESV), stroke volume (SV), ejection fraction (EF), and LV mass. The LV remodelling index was calculated as LV mass/EDV. At the same time, the enddiastolic endocardium and epicardium of the short axis and two long-axis sections were drawn to analyse the LV strain parameters (Fig. 2), including LV radial global peak strain (GRPS), circumferential global peak strain (GCPS), longitudinal global peak strain (GLPS) and the peak strain rates in these three directions during systole (PSSR) and diastole (PDSR).

\section{Statistical analysis}

Statistical analyses were performed with IBM SPSS (version 22.0, IBM SPSS Inc., Armonk, New York, US). All continuous variables were checked for normality using the Kolmogorov-Smirnov test. Normally distributed data are presented as the mean \pm standard deviation, while nonnormally distributed variables are presented as the median and interquartile range. One-way analysis of variance (one-way ANOVA) and Kruskal-Wallis tests were used to compare the baseline characteristics and CMR parameters among the normal, HTN (T2DM-) and $\mathrm{HTN}(\mathrm{T} 2 \mathrm{DM}+)$ groups. One-way ANOVA was used
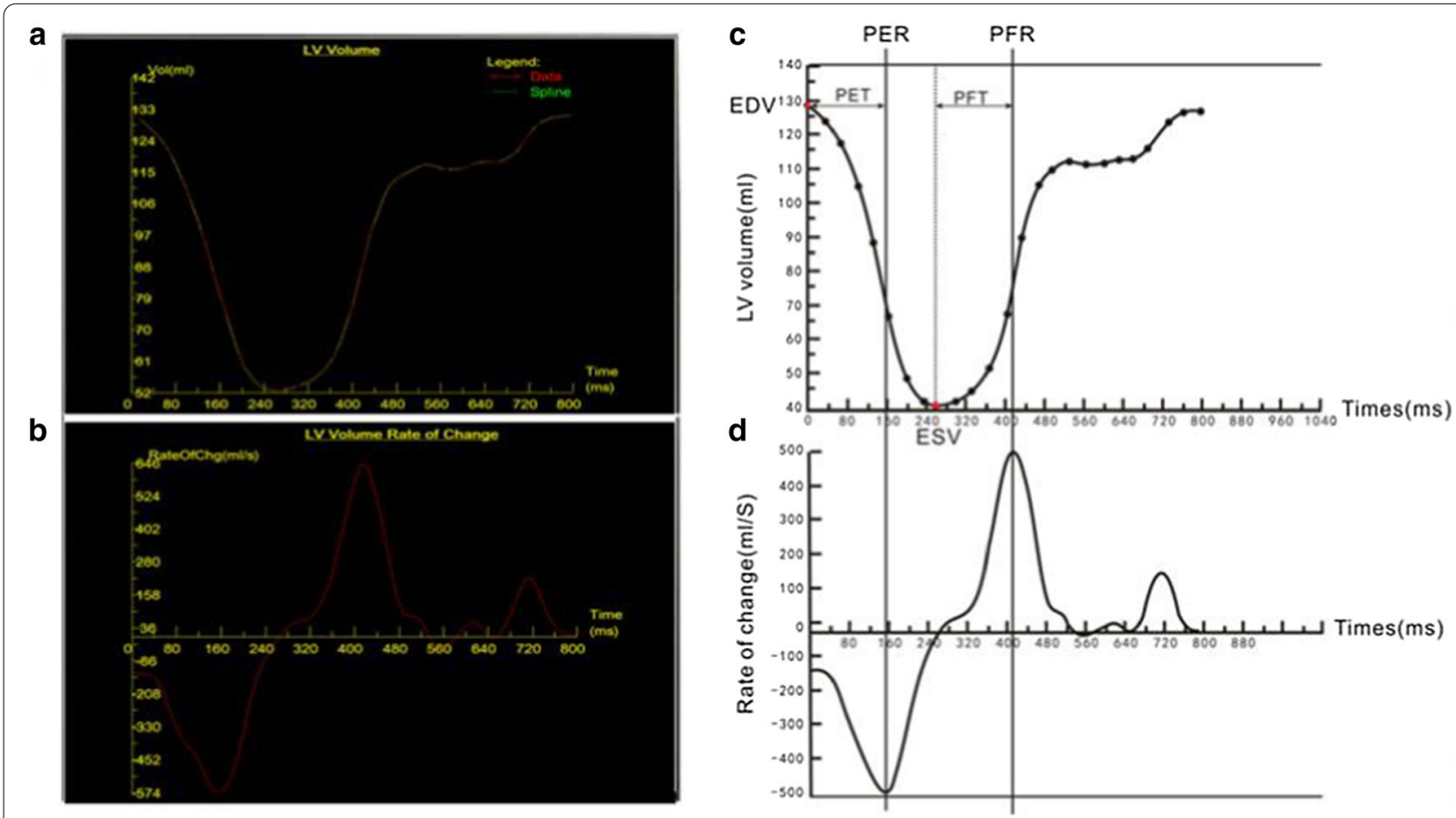

Fig. 1 a, b. Volume-time curves (a) and first derivatives (dV/dt) (b) depicted by Argus. c, $\mathbf{d}$ The meaning of volume-time curves parameters: peak ejection rate (PER) and peak filling rate (PFR) were determined as peak incremental volume changes, where volume-time curve was steepest, first derivative (dV/dt) was maximal positive or negative 


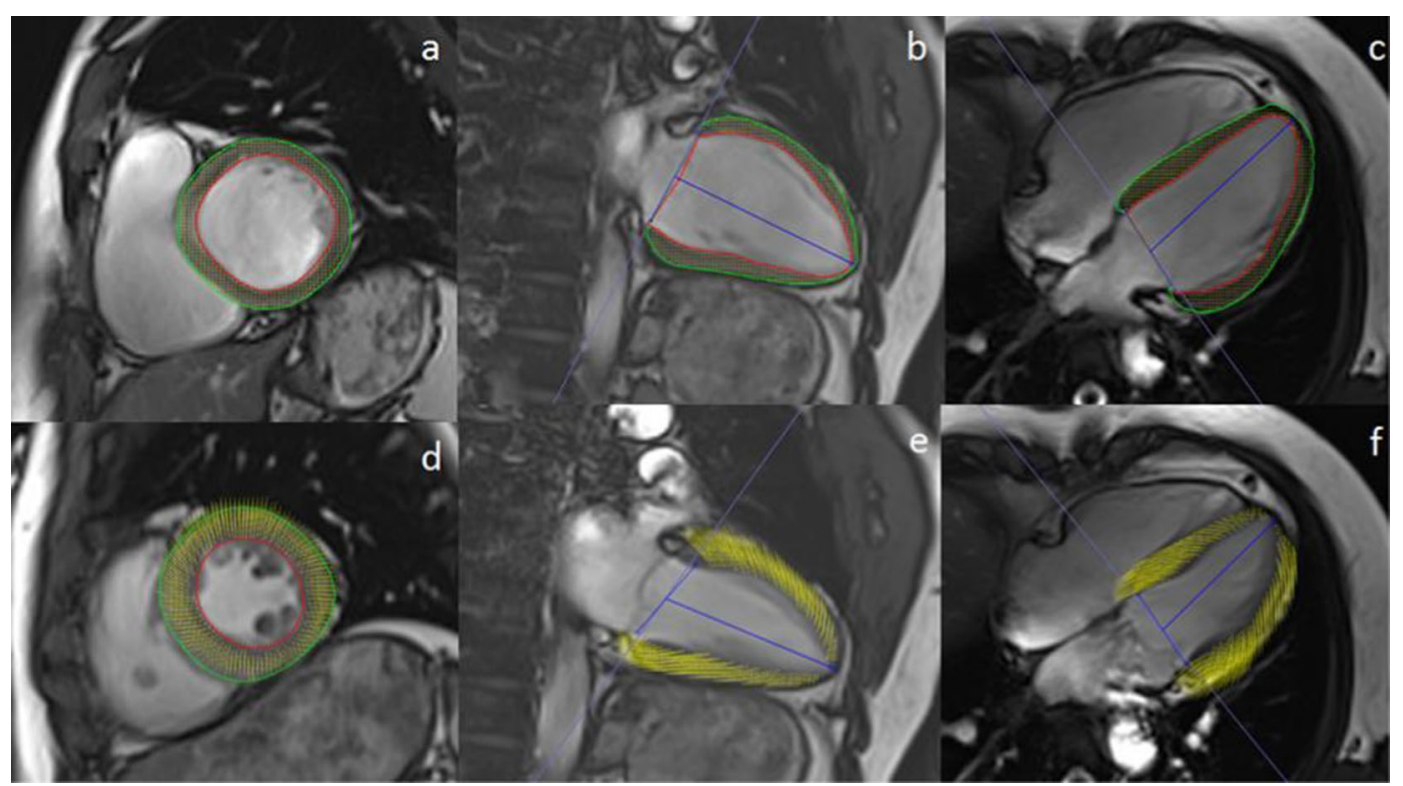

Fig. 2 Cardiac magnetic resonance tissue tracking in short-axis and long-axis two-chamber and four-chamber cine images at end-diastole (a-c) and end-systole (d-f)

when the data conformed to the homogeneity of variance and normal distribution assumptions, and the one-way ANOVA was followed by the Student-Newman-Keuls test. Kruskal-Wallis tests were used when the data exhibited skewed distributions. Categorical variables are expressed as frequencies (percentages) and were analysed using the chi-square test. Univariate and multivariate linear regression analyses were used to identify independent correlates of volume-time curve parameters and the basic clinical data. All candidate variables for linear regression analyses were selected based on clinical grounds, and those with a $\mathrm{p}$ value $<0.1$ in the univariate analysis were included in the stepwise multivariable linear regression analysis. The relationship between the volume-time curve and myocardial strain was analysed by Pearson correlation. Inter- and intra-observer agreements were determined by the evaluation of intraclass correlation coefficients (ICCs). A two-tailed $\mathrm{p}$ value $<0.05$ was considered significant for all statistical tests.

\section{Results}

\section{Study population and clinical baseline characteristics}

A comparison of basic characteristics among the control, $\mathrm{HTN}(\mathrm{T} 2 \mathrm{DM}-)$, and $\mathrm{HTN}(\mathrm{T} 2 \mathrm{DM}+)$ groups is presented in Table 1. Age, sex, body surface area (BSA), plasma triglycerides, high-density lipoprotein cholesterol, and estimated glomerular filtration rate (eGFR) were not significantly different between the observed groups (all $\mathrm{p}>0.05$ ), but body mass index (BMI) was higher in both the $\operatorname{HTN}(\mathrm{T} 2 \mathrm{DM}-)$ and $\operatorname{HTN}(\mathrm{T} 2 \mathrm{DM}+)$ groups than in the control group (all $\mathrm{p}<0.01$ ). There was no significant difference in the course of hypertension between the essential hypertension patients with or without T2DM.

\section{Comparison of LV function and time-volume curve parameters}

The CMR findings for the observed groups are shown in Table 2. With the exception of the myocardial mass and $\mathrm{LV}$ remodelling index in both the HTN(T2DM -) and $\mathrm{HTN}(\mathrm{T} 2 \mathrm{DM}+)$ groups being significantly higher than that of the control group (all $\mathrm{p}<0.001$ ), there was no significant difference in routine CMR parameters among the three groups. GLPS deteriorated from the control group to the HTN(T2DM - ) and HTN(T2DM +) groups.

During cardiac systole, there was no significant difference in volume-time curve parameters among the three groups. During diastole, PFT in the HTN(T2DM-) group and the $\mathrm{HTN}(\mathrm{T} 2 \mathrm{DM}+)$ group were longer than those in the control group, while both the PFR and PFR/EDV values were the lowest in the HTN(T2DM+) group, followed by the HTN(T2DM-) group, with the normal control group having the largest values; all comparisons were statistically significant (all $\mathrm{p}<0.05$ ). The typical LV filling patterns of the three groups of subjects are shown in Fig. 3. 
Table 1 Basic characteristics of normal controls, essential hypertension patients with diabetes and without diabetes

\begin{tabular}{|c|c|c|c|}
\hline & $\begin{array}{l}\text { Controls } \\
n=52\end{array}$ & $\begin{array}{l}\text { HTN (T2DM-) } \\
\mathrm{n}=76\end{array}$ & $\begin{array}{l}\mathrm{HTN}(\mathrm{T} 2 \mathrm{DM}+) \\
\mathrm{n}=48\end{array}$ \\
\hline \multicolumn{4}{|l|}{ Demographics } \\
\hline Age, years & $52.7 \pm 13.1$ & $56.4 \pm 14.22$ & $57.69 \pm 12.46$ \\
\hline Female, n (\%) & $26(50.0 \%)$ & $37(48.7 \%)$ & $24(50 \%)$ \\
\hline $\mathrm{BMI}\left(\mathrm{kg} / \mathrm{m}^{2}\right)$ & $22.6 \pm 2.9$ & $24.9 \pm 2.9^{*}$ & $24.2 \pm 2.6^{*}$ \\
\hline $\mathrm{BSA}\left(\mathrm{m}^{2}\right)$ & $1.65 \pm 0.18$ & $1.7 \pm 0.16$ & $1.68 \pm 0.13$ \\
\hline \multicolumn{4}{|l|}{ Hemodynamic variables } \\
\hline Systolic blood pressure $(\mathrm{mm} \mathrm{Hg})$ & $114.8 \pm 10.1$ & $143.2 \pm 20.7^{*}$ & $140.9 \pm 18.3^{*}$ \\
\hline Diastolic blood pressure $(\mathrm{mm} \mathrm{Hg})$ & $73.2 \pm 8.6$ & $85.3 \pm 16.5^{*}$ & $81.6 \pm 10.2^{*}$ \\
\hline \multicolumn{4}{|l|}{ Laboratory data } \\
\hline Fasting bloodglucose (mmol/L) & $5.21 \pm 1.66$ & $5.15 \pm 0.7$ & $8.04 \pm 3.24^{*}, \#$ \\
\hline $\mathrm{HbA} 1 \mathrm{c},(\%)$ & $5.27 \pm 0.36$ & $5.58 \pm 0.25$ & $6.86 \pm 0.97^{*}, \#$ \\
\hline Plasma triglycerides (mmol/L) & $1.35 \pm 0.51$ & $1.49 \pm 1.08$ & $1.32 \pm 0.55$ \\
\hline Total cholesterol (mmol/L) & $4.71 \pm 0.96$ & $4.44 \pm 0.89$ & $4.01 \pm 1.87$ \\
\hline $\mathrm{HDL}(\mathrm{mmol} / \mathrm{L})$ & $1.34 \pm 0.33$ & $1.32 \pm 0.48$ & $1.34 \pm 1.37$ \\
\hline $\mathrm{LDL}(\mathrm{mmol} / \mathrm{L})$ & $2.55 \pm 0.76$ & $2.53 \pm 0.72$ & $2.38 \pm 1.11$ \\
\hline eGFR (mL/min/1.73 m2) & $101.29 \pm 16.8$ & $96.86 \pm 20.04$ & $90.66 \pm 29.39$ \\
\hline \multicolumn{4}{|l|}{ HTN treatment } \\
\hline HTN duration (years) & - & $6.8 \pm 7.9$ & $5.7 \pm 5.6$ \\
\hline ACEI/ARB, n (\%) & - & $28(40)$ & $15(35)$ \\
\hline Beta-blocker, n (\%) & - & $28(40)$ & $16(40)$ \\
\hline Calcium channel blocker, n (\%) & - & $40(55.7)$ & $20(47.5)$ \\
\hline Diuretics, n (\%) & - & $11(15)$ & $6(15)$ \\
\hline \multicolumn{4}{|l|}{ Diabetes treatment } \\
\hline Diabetes duration (years) & - & - & $8.22 \pm 4.07$ \\
\hline Oral, n (\%) & - & - & $40(80.2)$ \\
\hline Insulin, n (\%) & - & - & $7(15.6)$ \\
\hline
\end{tabular}

The values are the mean $\pm S D$, Numbers in the brackets are percentages

HTN hypertension, T2DM type 2 diabetes mellitus, BMI body mass index, BSA body surface area, $H D L$ high-density lipoprotein cholesterol, $L D L$ low-density lipoprotein cholesterol, eGFR estimated glomerular filtration rate, $A C E I$ angiotensin converting enzyme inhibitor, $A R B$ angiotensin II receptor blocker

${ }^{*} p<0.05$ versus controls

$\# P<0.05$ versus HTN (T2DM-) group

\section{Regression analysis of LV diastolic function parameters in hypertension patients}

As shown in Table 3, age, sex, BSA, diabetes, HR, SP, and eGFR were initially screened based on clinical grounds and were assessed using univariable analysis. Univariate linear regression analyses showed that HR had a positive effect on the PFR/EDV $(\beta=0.027 ; 95 \%$ confidence interval $[\mathrm{CI}], 0.019$ to $0.035 ; \mathrm{P}<0.001)$ and that age $(\beta=-0.016 ; 95 \% \mathrm{CI}-0.024$ to $-0.008 ; \mathrm{P}<0.001)$, male $\operatorname{sex}(\beta=-0.377 ; 95 \% \mathrm{CI} \quad-0.594$ to $-0.161 ; \mathrm{P}=0.01)$ and diabetes $(\beta=-0.429 ; 95 \% \mathrm{CI}-0.669$ to -0.189 ; $\mathrm{P}=0.010$ ) had a negative effect on the PEF/EDV. Multivariable linear regression analyses demonstrated that considering the covariates of age, sex, BSA, and heart rate, T2DM was independently associated with PFR/EDV $\left(\beta=-0.186, \mathrm{p}=0.037\right.$, model $\left.\mathrm{R}^{2}=0.432\right)$.

\section{Correlations between time-volume curve parameters and LV global strain parameters}

As shown in Table 4 and Fig. 4, significant linear correlations were observed between time-volume curve parameters and LV global strain parameters. In particular, there was a clear association between the circumferential myocardial strain rate and the volume change rate. Circumferential PSSR and circumferential PSDR were significantly correlated with PER/EDV $(r=-0.795, \mathrm{p}<0.001)$ and PFR/EDV $(\mathrm{r}=0.756, \mathrm{p}<0.001)$, respectively.

\section{Intra- and interobserver variability}

As demonstrated in Table 5, there were excellent intraand interobserver agreements in the measurement of time-volume curve parameters $(\mathrm{ICC}=0.885 \sim 0.937$ and $0.831 \sim 0.916$, respectively). 
Table 2 Comparisons of CMR findings between controls, HTN (T2DM -) group and HTN (T2DM+) group

\begin{tabular}{|c|c|c|c|c|}
\hline & $\begin{array}{l}\text { Controls } \\
n=52\end{array}$ & $\begin{array}{l}\mathrm{HTN}(\mathrm{T} 2 \mathrm{DM}-) \\
\mathrm{n}=76\end{array}$ & $\begin{array}{l}\text { HTN }(\text { T2DM }+) \\
\mathrm{n}=48\end{array}$ & $P$ value \\
\hline \multicolumn{5}{|c|}{ CMR-derived cardiac geometric and functional parameters } \\
\hline Heart rate (beats/min) & $69.2 \pm 11.3$ & $73.5 \pm 14.3$ & $71.82 \pm 12.33$ & 0.196 \\
\hline LVEF (\%) & $70.8 \pm 4.9$ & $71.3 \pm 8.1$ & $69 \pm 9.3$ & 0.326 \\
\hline LVEDVI $\left(\mathrm{ml} / \mathrm{m}^{2}\right)$ & $68.21 \pm 12.09$ & $70.16 \pm 14.8$ & $70.24 \pm 11.76$ & 0.702 \\
\hline LVESVI $\left(\mathrm{ml} / \mathrm{m}^{2}\right)$ & $20.33 \pm 7.27$ & $20.91 \pm 9.56$ & $22.06 \pm 8.47$ & 0.626 \\
\hline LVSVI (ml/m²) & $47.89 \pm 6.71$ & $49.25 \pm 8.33$ & $48.18 \pm 9.25$ & 0.641 \\
\hline LVMASS(g) & $83.30 \pm 23.23$ & $102.4 \pm 33.3^{*}$ & $100.4 \pm 27.50^{*}$ & 0.000 \\
\hline Standardized Left Ventricular Mass $\left(\mathrm{g} / \mathrm{m}^{2}\right)$ & $47.92 \pm 12.16$ & $59.7 \pm 15.65^{*}$ & $56.6 \pm 15.4^{*}$ & 0.000 \\
\hline LV-remodeling index (g/ml) & $0.73 \pm 0.15$ & $0.83 \pm 0.14^{*}$ & $0.89 \pm 0.16^{*}$ & 0.000 \\
\hline \multicolumn{5}{|c|}{ CMR volume-time curve parameters of left ventricle } \\
\hline $\operatorname{PER}(\mathrm{ml} / \mathrm{s})$ & $387.48 \pm 99.63$ & $417.89 \pm 115.86$ & $384.42 \pm 92.66$ & 0.088 \\
\hline PET (ms) & $109.07 \pm 23.84$ & $103.46 \pm 29.01$ & $110.76 \pm 30.52$ & 0.116 \\
\hline $\operatorname{PFR}(\mathrm{ml} / \mathrm{s})$ & $390.61 \pm 84.98$ & $357.8 \pm 95.9^{*}$ & $319.8 \pm 67.8^{*, \#}$ & 0.000 \\
\hline PFT (ms) & $124.88 \pm 24.43$ & $149.14 \pm 41.80^{*}$ & $158.42 \pm 36.9^{*}$ & 0.000 \\
\hline PER/EDV & $3.26 \pm 0.62$ & $3.57 \pm 0.89$ & $3.49 \pm 0.66$ & 0.154 \\
\hline PFR/EDV & $3.45 \pm 0.55$ & $3.05 \pm 0.75^{*}$ & $2.78 \pm 0.69^{*, \#}$ & 0.000 \\
\hline \multicolumn{5}{|l|}{ CMR strain parameters of left ventricle } \\
\hline \multicolumn{5}{|l|}{ PS (\%) } \\
\hline Radial & $38.89 \pm 8.37$ & $37.57 \pm 12.22$ & $36.0 \pm 10.59$ & 0.552 \\
\hline Circumferential & $-21.1 \pm 2.86$ & $-21.1 \pm 2.89$ & $-20.26 \pm 3.68$ & 0.170 \\
\hline Longitudinal & $-15.13 \pm 2.64$ & $-13.90 \pm 2.83^{*}$ & $-11.91 \pm 3.62^{* \#}$ & 0.004 \\
\hline \multicolumn{5}{|l|}{$\operatorname{PSSR}(1 / \mathrm{S})$} \\
\hline Radial & $1.94 \pm 0.58$ & $2.11 \pm 0.79$ & $2.06 \pm 0.99$ & 0.822 \\
\hline Circumferential & $-1.01 \pm 0.20$ & $-1.08 \pm 0.27$ & $-0.92 \pm 0.50^{\#}$ & 0.041 \\
\hline Longitudinal & $-0.68 \pm 0.34$ & $-0.81 \pm 0.25$ & $-0.61 \pm 0.5$ & 0.232 \\
\hline \multicolumn{5}{|l|}{$\operatorname{PDSR}(1 / \mathrm{s})$} \\
\hline Radial & $-2.62 \pm 1.30$ & $-2.54 \pm 1.27$ & $-2.09 \pm 0.90^{*}$ & 0.031 \\
\hline Circumferential & $1.30 \pm 0.26$ & $1.41 \pm 0.38$ & $1.12 \pm 0.23^{* \#}$ & 0.007 \\
\hline Longitudinal & $0.91 \pm 0.26$ & $0.96 \pm 0.28$ & $0.84 \pm 0.33$ & 0.574 \\
\hline
\end{tabular}

HTN hypertension, T2DM type 2 diabetes mellitus, LV left ventricular, EF ejection fraction, EDV end diastolic volume, ESV end systolic volume, SV stroke volume, I indexed to BSA, PET time to peak ejection rate, PFT time to peak filling rate from end-systole, PER peak ejection rate, PFR peak filling rate, PS peak strain, $P S S R$ peak systolic strain rate, $P D S R$ peak diastolic strain rate

${ }^{*} p<0.05$ versus controls;

\# $p<0.05$ versus HTN (T2DM-) group

\section{Discussion}

Hypertension is the most common cardiovascular risk factor involving multiple systems and causes organ and tissue damage. Heart failure is one of the complications most closely related to blood pressure [16]. As a common metabolic disease, T2DM also has adverse effects on the heart and often coexists with essential hypertension $[17,18]$. In this study, our main findings are as follows: (1) LV diastolic function was impaired in patients with essential hypertension, even in the absence of clinical evidence of heart failure; (2) T2DM aggravated LV diastolic dysfunction in patients with essential hypertension; and (3) in both systolic and diastolic phases, myocardial circumferential strain had the greatest influence on LV volume.

Based on our results, compared with the respective findings in the normal control group, the PFR and PER/ EDV were lower and PFT was significantly prolonged in the HTN(T2DM-) group. These changes represent the deterioration of LV diastolic function in hypertensive patients [19]. Extensive research has shown that when hypertension exists as a single factor, its effect on the heart is mainly reflected in the abnormal accumulation of fibrous collagen and compensatory LV hypertrophy caused by chronically increased LV workload [20]. Once these changes cause myocardial relaxation to slow down, 

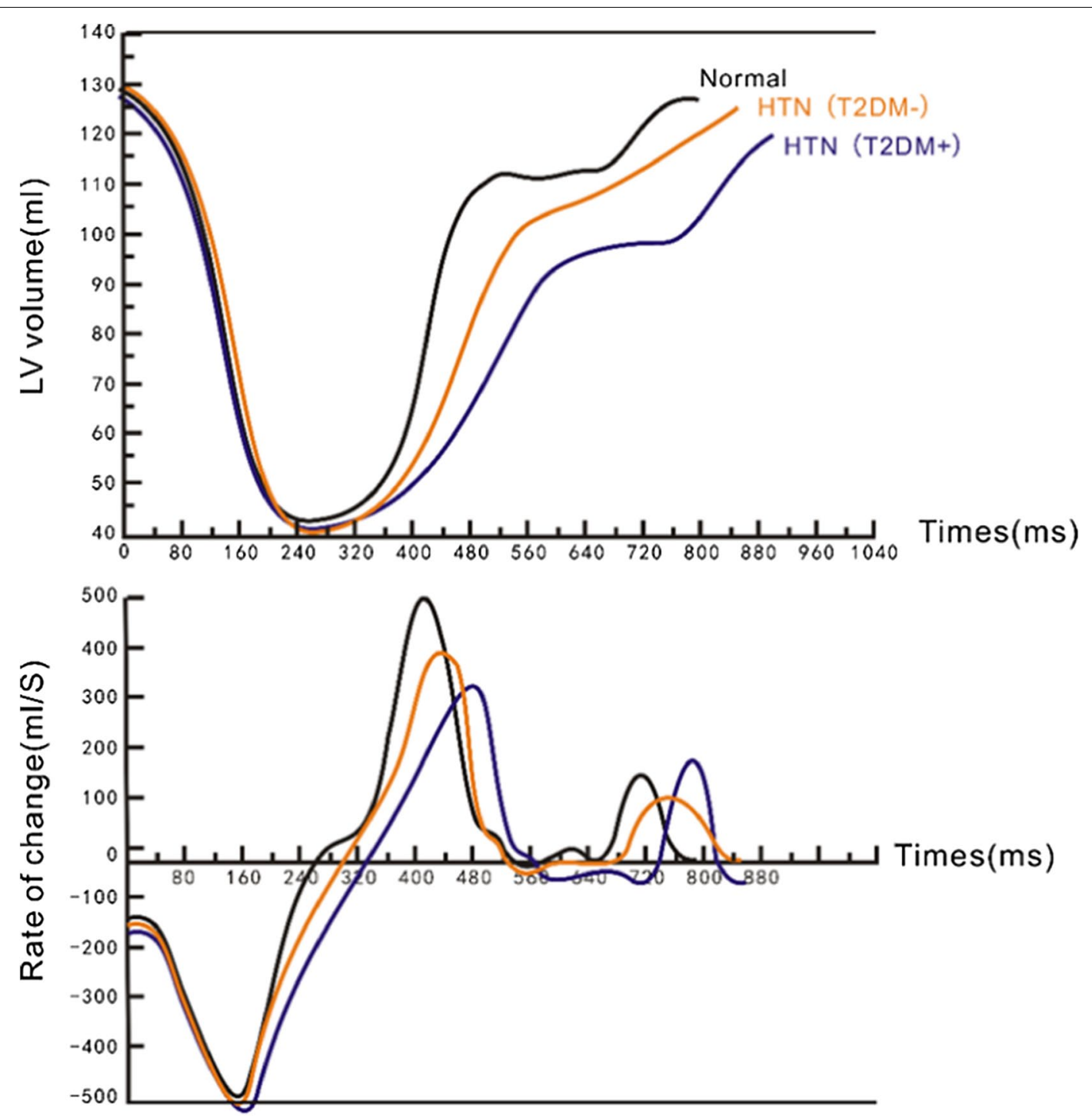

Fig. 3 Comparison of LV volume-time curves in healthy participants (normal) and patients. HTN hypertension, T2DM type 2 diabetes mellitus, LV left ventricular

Table 3 Univariable and multivariable linear regression analysis of PFR/EDV in all HTN patients $(n=124)$

\begin{tabular}{|c|c|c|c|c|c|}
\hline & \multicolumn{2}{|c|}{ Univariable } & \multicolumn{3}{|c|}{ Multivariable } \\
\hline & $\bar{\beta}$ & $P$ value & $\bar{\beta}$ & Pvalue & $\mathrm{R}^{2}$ \\
\hline Age (y) & -0.016 & 0.000 & -0.241 & 0.001 & 0.432 \\
\hline Sex (female) & -0.259 & 0.01 & -0.234 & 0.005 & \\
\hline BSA & -0.087 & 0.931 & - & - & \\
\hline Diabetes & -0.186 & 0.044 & -0.252 & 0.037 & \\
\hline $\mathrm{HR}$ & 0.027 & 0.000 & 0.410 & 0.000 & \\
\hline $\mathrm{SP}$ & 0.018 & 0.17 & - & - & \\
\hline eGFR & 0.144 & 0.183 & - & - & \\
\hline
\end{tabular}

HTN hypertension, BSA body surface area, HR heart rate. Variables for multivariable model were selected on clinical grounds, guided by univariable correlation with $\mathrm{P}$ value $<0.10$ and the absence of collinearity
LV diastolic function is impaired [21]. Although patients with an $\mathrm{EF}<50 \%$ and/or myocardial infarction were strictly excluded, our findings in patients with essential hypertension alone are consistent with findings of previous echocardiography studies [22, 23]. At present, echocardiography is the primary method for the clinical evaluation of cardiac diastolic function, and it has been widely used in scientific research [24, 25]. However, in some special cases, such as obesity, chronic obstructive pulmonary disease and patients with chest pain or recent surgery, echocardiography has limitations. With the advancement of scanning and postprocessing techniques, CMR is expected to become another important imaging method in this field $[26,27]$. 
Table 4 Correlation analysis of LV global strain parameters with the time-volume curve parameters

\begin{tabular}{|c|c|c|c|c|c|c|c|c|}
\hline & \multicolumn{2}{|l|}{ PER } & \multicolumn{2}{|l|}{ PFR } & \multicolumn{2}{|l|}{ PER/EDV } & \multicolumn{2}{|l|}{ PFR/EDV } \\
\hline & r & P value & $r$ & $P$ value & $r$ & Pvalue & $r$ & $P$ value \\
\hline \multicolumn{9}{|l|}{ PS (\%) } \\
\hline Radial & -0.012 & 0.89 & 0.04 & 0.648 & $.414 \#$ & 0.000 & $.449 \#$ & 0.000 \\
\hline Circumferential & -0.006 & 0.946 & $-.219^{*}$ & 0.011 & $-.391 \#$ & 0.000 & $-.588 \#$ & 0.000 \\
\hline Longitudinal & 0.146 & 0.092 & -0.097 & 0.267 & $-.226 \#$ & 0.009 & $-.467 \#$ & 0.000 \\
\hline \multicolumn{9}{|l|}{$\operatorname{PSSR}(1 / \mathrm{s})$} \\
\hline Radial & 0.161 & 0.063 & -0.019 & 0.829 & $.603 \#$ & 0.000 & $.372 \#$ & 0.000 \\
\hline Circumferential & $-.329 \#$ & 0.000 & -0.047 & 0.588 & $-.795 \#$ & 0.000 & $-.407 \#$ & 0.000 \\
\hline Longitudinal & $-.186^{*}$ & 0.031 & -0.087 & 0.315 & $-.288 \#$ & 0.001 & -0.141 & 0.103 \\
\hline \multicolumn{9}{|l|}{$\operatorname{PDSR}(1 / \mathrm{s})$} \\
\hline Radial & 0.084 & 0.334 & $-.254 \#$ & 0.003 & $-.197^{*}$ & 0.022 & $-.549 \#$ & 0.000 \\
\hline Circumferential & -0.009 & 0.918 & $.412 \#$ & 0.000 & $.358 \#$ & 0.000 & $.756 \#$ & 0.000 \\
\hline Longitudinal & -0.11 & 0.206 & 0.138 & 0.113 & $.302 \#$ & 0.000 & $.540 \#$ & 0.000 \\
\hline
\end{tabular}

Abbreviation of PET, PFT, PER, PFR, PS, PSSR, PDSR, are shown in Table 2

${ }^{*} p<0.05 ; \# p<0.01$

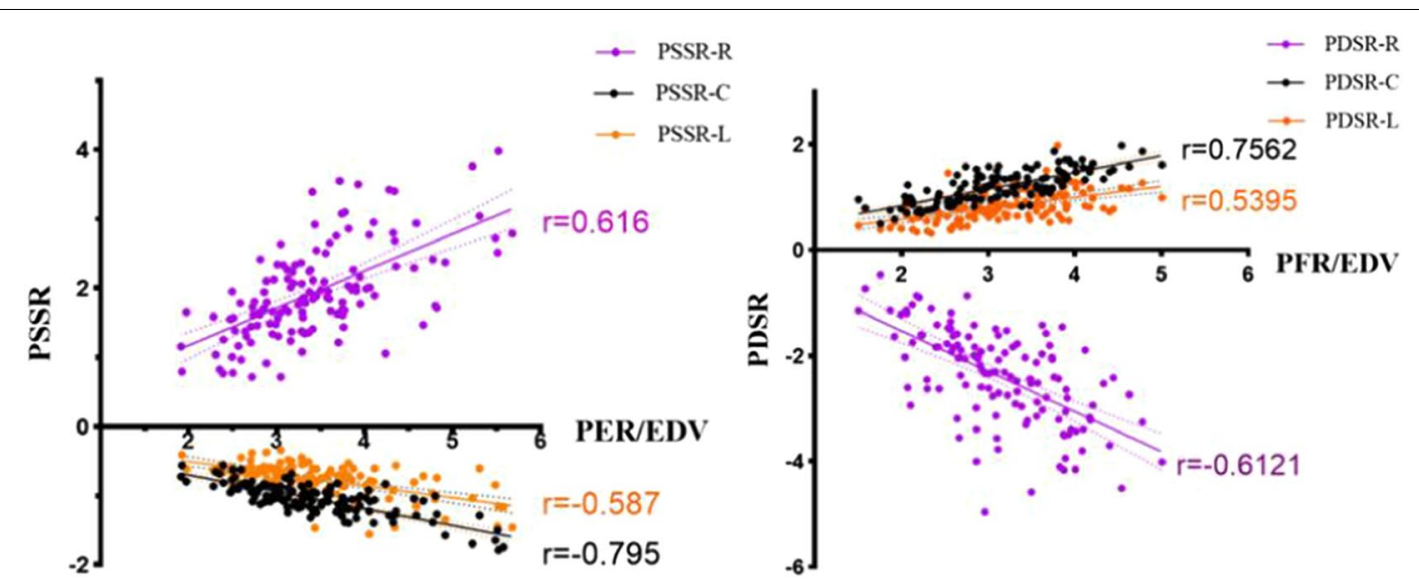

Fig. 4 The relationship between peak strain rate in different directions and normalized peak volume change rate. EDV end diastolic volume, $P E R$ peak ejection rate, PFR peak filling rate, PSSR peak systolic strain rate, PDSR peak diastolic strain rate, $R$ radial, $C$ circumferential, $L$ longitudinal

Table 5 Inter- and intra-observer variability of time-volume curve

\begin{tabular}{llllll}
\hline & \multicolumn{2}{l}{ Intra-observer $(\mathrm{n}=30)$} & & \multicolumn{2}{l}{ Inter-observer $(\mathrm{n}=30)$} \\
\cline { 2 - 3 } \cline { 6 - 7 } & ICC & $95 \% \mathrm{Cl}$ & & ICC & $95 \% \mathrm{Cl}$ \\
\hline PET & 0.885 & $0.828-0.943$ & & 0.831 & $0.735-0.899$ \\
PFT & 0.898 & $0.865-0.934$ & & 0.852 & $0.796-0.912$ \\
PER & 0.887 & $0.873-0.924$ & & 0.879 & $0.852-0.898$ \\
PFR & 0.937 & $0.895-0.976$ & & 0.916 & $0.865-0.942$ \\
\hline
\end{tabular}

ICC intraclass correlation coefficient, $\mathrm{Cl}$ confidence interval; Abbreviation of PET, PFT, PER, PFR are shown in Table 2

All $p<0.01$
When patients with essential hypertension are complicated with T2DM, we found that PFR and PFR/EDV were further decreased in $\operatorname{HTN}(\mathrm{T} 2 \mathrm{DM}+)$ patients compared with the same parameters in HTN(T2DM-) patients. In addition, after considering confounders such as age, sex, and BSA, the adverse effects of T2DM on the LV diastolic function of patients with hypertension remained. Previous studies have shown that due to many individual or common pathophysiological factors, such as myocardial hypertrophy, cardiac steatosis, interstitial fibrosis, and myocardial energetic impairment, an adverse positive feedback cycle exists between hypertension 
and T2DM [28-31]. Although the interaction between various factors has not been fully elucidated, systemic vascular dysfunction and endocrine-related microcirculation disorders are considered to play essential roles $[32,33]$. In the early stages of cardiac damage associated with only diastolic dysfunction, these adverse effects are often difficult to identify using routine cardiac function parameters. Nevertheless, the differences in LV filling patterns shown by the volume-time curve between HTN(T2DM+) and HTN(T2DM-) in this study could intuitively indicate that T2DM further reduces LV compliance in hypertensive patients during passive diastole.

Despite the use of antihypertensive drugs, the LV mass and remodelling index in our patients with essential hypertension were higher than those in the participants in the normal group. This result is consistent with previous studies that indicated that myocardial remodelling independent of antihypertensive effects could occur over a longer time [32, 34]. In addition to cardiac load, several previous studies have shown that abnormal glucose metabolism and insulin resistance also lead to adverse remodelling of the heart [35-37]. However, there was no significant difference in the LV remodelling index between the HTN(T2DM-) group and $\operatorname{HTN}(\mathrm{T} 2 \mathrm{DM}+$ ) group according to our results. This nonsynchronization of function and morphology suggests that T2DM has adverse effects on LV diastolic function in essential hypertension patients, even if the overall cardiac structure has not been further changed.

In recent years, myocardial strain has been considered a reliable index to evaluate cardiac function [38]. By analysing the correlation between the volume-time curve and myocardial strain, we further confirmed that myocardial strain in different directions has different degrees of association with LV volume. Previous investigators have found that circumferential motion contributes twice as much to EF as longitudinal motion [39]. In this study, we analysed the correlation of longitudinal, radial, circumferential peak strain rates of systole and diastole with the peak volume change rates of the corresponding cardiac phase and demonstrated that the LV volume is most related to the circumferential motion of the myocardium in both the systolic and diastolic periods. Other echocardiographic studies have shown that many diseases, including essential hypertension and T2DM, are most likely to cause changes in the subendocardium, which is mainly composed of longitudinally oriented fibres [4042]. Thus, our results may explain from another point of view why GLPS could detect slight myocardial deterioration, but the diseases that lead to these abnormalities result in no significant reduction in EF.

There are some limitations in our research. First, as a single-centre study, we adhered to strict inclusion and exclusion criteria to limit the influence of confounding factors, which resulted in a reduced sample size. Second, this study confirmed that the volume-time curve is sensitive to subclinical LV diastolic dysfunction, but it is still necessary to further explore its specific application in different clinical diseases. Finally, since this is a retrospective study, the evolution of the diseases needs to be discussed in further follow-up or prospective studies in the future.

\section{Conclusions}

T2DM aggravates the damage of LV diastolic function in essential hypertension patients, even in those without further remodelling of a cardiac structure. The change in LV filling pattern reflected by the CMR volume-time curve could reflect this adverse effect earlier than conventional cardiac function parameters, which may provide more valuable information for clinical treatment.

\section{Abbreviations \\ HTN: Hypertension; T2DM: Type to diabetes mellitus; LV: Left ventricular; CMR: Cardiac magnetic resonance; EDV: End-diastolic volume; ESV: End-diastolic vol- ume; EF: Left ventricular ejection fraction; SV: Stroke volume; I: Indexed to BSA; PET: Time to peak ejection rate; PFT: Time to peak filling rate from end-systole; PER: Peak ejection rate; PFR: Peak filling rate; PS: Peak Strain; PSSR: Peak Systolic Strain Rate; PDSR: Peak Diastolic Strain Rate.}

\section{Acknowledgements}

Not applicable.

\section{Authors' contributions}

WFY, YG and YZ designed the study. WFY analyzed the data and wrote the manuscript. YKG participated in the study design, data analyze, editing and review of the manuscript. ZGY and $Y L$ supervised the overall study and contributed to study design, editing and review of the manuscript. JW, LJ were responsible for collecting, sorting and statistical data. ZGY is the guarantor of this work and, as such, had full access to all the data in the study and takes responsibility for the integrity of the data and the accuracy of the data analysis. All authors read and approved the final manuscript.

\section{Funding}

This work was supported by a grant from the National Natural Science Foundation of China $(81771887,81471722,81971586$ and 81771897$)$ and $1 \cdot 3 \cdot 5$ project for disciplines of excellence, West China Hospital, Sichuan University (ZYGD18013).

\section{Availability of data and materials}

The datasets used and analyzed during the current study are available from the corresponding author on reasonable request.

\section{Declarations}

\section{Ethics approval and consent to participate}

This study was approved by the Biomedical Research Ethics Committee of our Hospital, Sichuan University (Chengdu, Sichuan, China) with a waiver of informed consent due to the retrospective nature of this investigation.

\section{Consent for publication}

Not applicable. 


\section{Competing interests}

The authors declare that there are no conflicts of interest.

\section{Author details}

${ }^{1}$ Department of Radiology, West China Hospital, Sichuan University, 37\# Guo Xue Xiang, Chengdu 610041, Sichuan, China. ${ }^{2}$ Department of Radiology, Key Laboratory of Birth Defects and Related Diseases of Women and Children of Ministry of Education, West China Second University Hospital, Sichuan University, 20\# South Renmin Road, Chengdu, Sichuan 610041, P.R. China.

Received: 16 January 2021 Accepted: 16 March 2021

Published online: 25 March 2021

\section{References}

1. García-Puig J, Ruilope LM, Luque M, Fernández J, Ortega R, Dal-Ré R. Glucose metabolism in patients with essential hypertension. American Med. 2006;119:318-26.

2. Sciacqua A, Miceli S, Greco L, Arturi F, Naccarato P, Mazzaferro D, et al. One-hour postload plasma glucose levels and diastolic function in hypertensive patients. Diabetes Care. 2011;34:2291-6.

3. Kane GC, Karon BL, Mahoney DW, Redfield MM, Roger VL, Burnett JC, et al. Progression of left ventricular diastolic dysfunction and risk of heart failure. JAMA. 2011;306:856-63.

4. Yokota S, Tanaka H, Mochizuki Y, Soga F, Yamashita K, Tanaka Y, et al. Association of glycemic variability with left ventricular diastolic function in type 2 diabetes mellitus. Cardiovasc Diabetol. 2019;18:166.

5. Leiner T, Bogaert J, Friedrich MG, Mohiaddin R, Muthurangu V, Myerson S, et al. SCMR Position Paper (2020) on clinical indications for cardiovascular magnetic resonance. J Cardiovasc Magnetic Resonance. 2020;22:76.

6. Vasquez M, Nagel E. Clinical indications for cardiovascular magnetic resonance. Heart (British Cardiac Society). 2019;105:1755-62.

7. Rodríguez-Granillo GA, Mejía-Campillo M, Rosales MA, Bolzán G, Ingino C, López F, et al. Left ventricular filling patterns in patients with previous myocardial infarction measured by conventional cine cardiac magnetic resonance. Int J Cardiovasc Imaging. 2012;28:795-801.

8. Webb J, Fovargue L, Tøndel K, Porter B, Sieniewicz B, Gould J, et al. The emerging role of cardiac magnetic resonance imaging in the evaluation of patients with HFpEF. Curr Heart Fail Rep. 2018;15:1-9.

9. Ahtarovski KA, Iversen KK, Christensen TE, Andersson H, Grande P, Holmvang $L$, et al. Takotsubo cardiomyopathy, a two-stage recovery of left ventricular systolic and diastolic function as determined by cardiac magnetic resonance imaging. Eur Heart J Cardiovasc Imaging. 2014;15:855-62.

10. Chamsi-Pasha MA, Zhan Y, Debs D, Shah DJ. CMR in the evaluation of diastolic dysfunction and phenotyping of HFpEF: current role and future perspectives. JACC Cardiovasc Imaging. 2020;13:283-96.

11. Schoennagel BP, Fischer R, Grosse R, Berliner C, Wehbe M, Kurio G, et al. Peak filling rates assessed by CMR imaging indicate diastolic dysfunction from myocardial iron toxicity. JACC Cardiovasc Imaging. 2016;9:1353-4.

12. Xu HY, Yang ZG, Guo YK, Shi K, Liu X, Zhang Q, et al. Volume-time curve of cardiac magnetic resonance assessed left ventricular dysfunction in coronary artery disease patients with type 2 diabetes mellitus. BMC Cardiovasc Disord. 2017;17:145.

13. Williams B, Mancia G, Spiering W, Agabiti Rosei E, Azizi M, Burnier M, et al. 2018 ESC/ESH Guidelines for the management of arterial hypertension. Eur Heart J. 2018:39:3021-104

14. Chamberlain JJ, Herman WH, Leal S, Rhinehart AS, Shubrook JH, Skolnik N, Kalyani RR. Pharmacologic therapy for type 2 diabetes: synopsis of the 2017 American diabetes association standards of medical care in diabetes. Ann Intern Med. 2017;166:572-8.

15. Schulz-Menger J, Bluemke DA, Bremerich J, Flamm SD, Fogel MA, Friedrich $M G$, et al. Standardized image interpretation and post-processing in cardiovascular magnetic resonance - 2020 update: Society for Cardiovascular Magnetic Resonance (SCMR): Board of Trustees Task Force on Standardized Post-Processing. J Cardiovasc Magnetic Resonance. 2020;22:19.

16. Rapsomaniki E, Timmis A, George J, Pujades-Rodriguez M, Shah AD, Denaxas $\mathrm{S}$, et al. Blood pressure and incidence of twelve cardiovascular diseases: Lifetime risks, healthy life-years lost, and age-specific associations in 1.25 million people. Lancet. 2014;383:1899-911.
17. Lindman BR, Dávila-Román VG, Mann DL, McNulty S, Semigran MJ, Lewis $\mathrm{GD}$, et al. Cardiovascular phenotype in HFpEF patients with or without diabetes: A RELAX trial ancillary study. J Am Coll Cardiol. 2014;64:541-9.

18. Lip S, Jeemon P, McCallum L, Dominiczak AF, Mclnnes GT, Padmanabhan S. Contrasting mortality risks among subgroups of treated hypertensive patients developing new-onset diabetes. Eur Heart J. 2016;37:968-74.

19. Kawaji K, Codella NC, Prince MR, Chu CW, Shakoor A, LaBounty TM, et al. Automated segmentation of routine clinical cardiac magnetic resonance imaging for assessment of left ventricular diastolic dysfunction. Circulation Cardiovascu Imaging. 2009;2:476-84.

20. González A, Ravassa S, López B, Moreno MU, Beaumont J, San José G, et al. Myocardial remodeling in hypertension. Hypertension. 2018;72:54958 (Dallas, Tex. : 1979).

21. Rodrigues JC, Am Amadu, Dastidar AG, Szantho GV, Lyen SM, Godsave C, et al. Comprehensive characterisation of hypertensive heart disease left ventricular phenotypes. Heart (British Cardiac Society). 2016. 102:1671-9.

22. Zeidan Z, Erbel R, Barkhausen J, Hunold P, Bartel T, BuckT. Analysis of global systolic and diastolic left ventricular performance using volumetime curves by real-time three-dimensional echocardiography. J American Society Echocardiography . 2003;16:29-37.

23. MarwickTH, Gillebert TC, Aurigemma G, Chirinos J, Derumeaux G, Galderisi M, et al. Recommendations on the use of echocardiography in adult hypertension: a report from the european association of cardiovascular imaging (EACVI) and the American Society of Echocardiography (ASE). J American Society Echocardiography. 2015;28:727-54

24. Nagueh SF, Smiseth OA, Appleton CP, Byrd BF, Dokainish H, Edvardsen $T$, et al. Recommendations for the evaluation of left ventricular diastolic function by echocardiography: an update from the american society of echocardiography and the European Association of Cardiovascular Imaging. J American Society Echocardiography. 2016;29:277-314.

25. Steele JM, Urbina EM, Mazur WM, Khoury PR, Nagueh SF, Tretter JT, Alsaied T. Left atrial strain and diastolic function abnormalities in obese and type 2 diabetic adolescents and young adults. Cardiovasc Diabetol. 2020;19:163.

26. Wu V, Chyou JY, Chung S, Bhagavatula S, Axel L. Evaluation of diastolic function by three-dimensional volume tracking of the mitral annulus with cardiovascular magnetic resonance: Comparison with tissue Doppler imaging. J Cardiovascu Magnetic Resonance. 2014;16:71.

27. Chen Q, Gan Y, Li ZY. Left ventricular diastolic dysfunction in type 2 diabetes patients: A novel 2D strain analysis based on cardiac magnetic resonance imaging. Comput Methods Biomech Biomed Engin. 2016;19:1330-8.

28. Konstam MA. Ventricular remodelling: An equal-opportunity prognosticator. European J Heart Failure. 2020. https://doi.org/10.1002/ejhf.1991.

29. Li XM, Jiang L, Guo YK, Ren Y, Han PL, Peng LQ, et al. The additive effects of type 2 diabetes mellitus on left ventricular deformation and myocardial perfusion in essential hypertension: A 3.0 T cardiac magnetic resonance study. Cardiovascu Diabetol. 2020;19:161.

30. Liu X, Yang ZG, Gao Y, Xie LJ, Jiang L, Hu BY, et al. Left ventricular subclinical myocardial dysfunction in uncomplicated type 2 diabetes mellitus is associated with impaired myocardial perfusion: A contrast-enhanced cardiovascular magnetic resonance study. Cardiovasc Diabetol. 2018;17:139.

31. Storz $C$, Hetterich $H$, Lorbeer $R$, Heber SD, Schafnitzel A, Patscheider $H$, et al. Myocardial tissue characterization by contrast-enhanced cardiac magnetic resonance imaging in subjects with prediabetes, diabetes, and normal controls with preserved ejection fraction from the general population. Eur Heart J Cardiovasc Imaging. 2018;19:701-8.

32. Climie RE, van Sloten TT, Bruno RM, Taddei S, Empana JP, Stehouwer CDA, et al. Macrovasculature and microvasculature at the crossroads between Type 2 diabetes mellitus and hypertension. Hypertension. 2019;73:113849 (Dallas, Tex. : 1979)

33. Sørensen MH, Bojer AS, Broadbent DA, Plein S, Madsen PL, Gæde P. Cardiac perfusion, structure, and function in type 2 diabetes mellitus with and without diabetic complications. Eur Heart J Cardiovasc Imaging. 2020;21:887-95.

34. Ong KT, Delerme S, Pannier B, Safar ME, Benetos A, Laurent S, et al. Aortic stiffness is reduced beyond blood pressure lowering by short-term and long-term antihypertensive treatment: A meta-analysis of individual data in 294 patients. J Hypertens. 2011;29:1034-42.

35. Markus MRP, Rospleszcz S, Ittermann T, Baumeister SE, Schipf S, SiewertMarkus $U$, et al. Glucose and insulin levels are associated with arterial 
stiffness and concentric remodeling of the heart. Cardiovasc Diabetol. 2019:18:145.

36. Rospleszcz S, Schafnitzel A, Koenig W, Lorbeer R, Auweter S, Huth C, et al. Association of glycemic status and segmental left ventricular wall thickness in subjects without prior cardiovascular disease: A cross-sectional study. BMC Cardiovasc Disord. 2018;18:162.

37. Ozasa N, Furukawa Y, Morimoto T, Tadamura E, Kita T, Kimura T. Relation among left ventricular mass, insulin resistance, and hemodynamic parameters in type 2 diabetes. Hypertension Res. 2008;31:425-32.

38. Claus P, Omar AMS, Pedrizzetti G, Sengupta PP, Nagel E. Tissue tracking technology for assessing cardiac mechanics: principles, normal values, and clinical applications. JACC Cardiovasc Imaging. 2015;8:1444-60.

39. Stokke TM, Hasselberg NE, Smedsrud MK, Sarvari SI, Haugaa KH, Smiseth $\mathrm{OA}$, et al. Geometry as a confounder when assessing ventricular systolic function: comparison between ejection fraction and strain. J Am Coll Cardiol. 2017;70:942-54.

40. Ishizu T, Seo Y, Kameda Y, Kawamura R, Kimura T, Shimojo N, et al. Left ventricular strain and transmural distribution of structural remodeling in hypertensive heart disease. Hypertension. 2014;63:500-6 (Dallas, Tex. : 1979).

41. Kalam K, Otahal P, Marwick TH. Prognostic implications of global LV dysfunction: A systematic review and meta-analysis of global longitudinal strain and ejection fraction. Heart (British Cardiac Society). 2014;100:1673-80.

42. Vinereanu D, Nicolaides E, Tweddel AC, Mädler CF, Holst B, Le Boden et al. Subclinical left ventricular dysfunction in asymptomatic patients with Type II diabetes mellitus, related to serum lipids and glycated haemoglobin. Clinical science (London, England: 1979). 2003.105:591-9.

\section{Publisher's Note}

Springer Nature remains neutral with regard to jurisdictional claims in published maps and institutional affiliations.
Ready to submit your research? Choose BMC and benefit from:

- fast, convenient online submission

- thorough peer review by experienced researchers in your field

- rapid publication on acceptance

- support for research data, including large and complex data types

- gold Open Access which fosters wider collaboration and increased citations

- maximum visibility for your research: over 100M website views per year

At BMC, research is always in progress.

Learn more biomedcentral.com/submissions 